\title{
Reseñas
}

\section{François Dubet:}

\section{Repensar la justicia social.Contra el mito de la igualdad de oportunidades.}

Buenos Aires: Siglo Veintiuno Editores, 2011.128 págs. (21x14 cm.).

Traducido por Alfredo Grieco y Bavio. ISBN 978-987-629-163-7

François Dubet: Rethinking social justice.

\section{Eva Vázquez}

Departamento de Planificación y

Políticas Públicas, UNLa

\section{Fecha de recepción:}

14 de junio de 2011

\section{Fecha de aceptación:}

15 de julio de 2011
El discurso político sobre la justicia social da cuenta de uno de los problemas que afectan a las ciencias sociales: el desajuste entre los cuerpos teóricos con los que trabajamos y las realidades socio históricas. Esto plantea la necesidad de una constante resignificación y construcción de nuevos conceptos teóricos que se aproximen mejor a la realidad y orienten las políticas, sobre todo aquellas que tienen que ver con la construcción de sociedades más justas.

Pensar lo nacional desde autores extranjeros puede ser controversial, forzado o incluso erróneo; sin embargo la mirada de François Dubet hacia lo que llama el mito de la igualdad de oportunidades nos ofrece un punto de vista novedoso bajo el que pueden pensarse las políticas públicas argentinas de los últimos diez años.

El autor contrapone dos modelos, el de la igualdad de lugares y el de igualdad de oportunidades. La igualdad de las posiciones se refiere a una visión de la sociedad que es pensada en términos de una estratificación socioprofesional y de clases sociales mientras que el modelo de igualdad de oportunidades define grupos sociales vulnerabales en función de las posibilidades objetivas para acceder a todas las posiciones. De acuerdo al autor el modelo 
de igualdad de las posiciones es el que se corresponde con el estado de bienestar mientras que el de igualdad de oportunidades es el que se viene desarrollando desde hace unos cuarenta años.

Dubet deja fuera de discusión la importancia de las labores llevadas a cabo por los "Estados de Bienestar" en función de la reducción de las inequidades sociales, pero resalta el problema que ellos generan: la fijación de las posiciones ocupadas en la escala social. La importancia de analizar los efectos no deseados de las políticas sociales dirigidas a la protección de ciertas posiciones sociales corre el riesgo de que se obture la posibilidad de reducir las desigualdades entre esas posiciones. La crítica central al modelo de igualdad de los lugares no está puesta en sus principios sino a las prácticas que genera y a sus consecuencias, más favorables para aquellos que ocupan en la sociedad posiciones seguras que para quienes no están integrados. En palabras del autor "No sólo la igualdad de los lugares no ha cumplido todas sus promesas, sino que, peor aún, ha engendrado nuevas injusticias" (pág. 51).

Respecto del modelo de igualdad de oportunidades, Dubet señala que está construido sobre la base de una ficción, la que indica que "los individuos se distribuyen proporcionalmente en todos los niveles de la estructura social sean cuales fueren sus orígenes y sus condiciones iniciales" (pág. 54). Se trata de un modelo basado en la idea de movilidad perfecta y que no considera las circunstancias desiguales de partida en la que se encuentran los miembros de las sociedades capitalistas actuales. El hecho de que un modelo de estado protector sea mejor en términos generales que otro tipo de estados no puede ser razón suficiente para que no se de la discusión acerca de una realidad que existe y que es la de una estructura social que presenta grandes desigualdades en su interior.

La perspectiva propuesta por el autor enriquece la mirada necesaria sobre un modelo de estado que si bien es a todas luces más justo e inclusivo que otros como el propulsado en los noventa, por ejemplo, tiene que seguir trabajando para achicar la brecha existente entre los que más y los que menos tienen. Este libro nos permite pensar nuestro actual modelo de estado desde sus propias premisas sin caer en críticas liberales. El desafío de darnos el ejercicio de pensar el actual proyecto nacional desde el mismo proyecto es una tarea indispensable para continuar construyendo una sociedad más justa.

En la Argentina actual pensar en hacer justicia social supone poner en práctica políticas que integren a los desafiliados, en el sentido que le asigna Robert Castel. En este sentido la Asignación Universal por Hijo (decreto 1602/09) es una medida inédita si se analiza desde una perspectiva histórica que busca actuar directamente sobre sectores hasta ahora excluidos y tiene la particularidad de operar sobre lo que Dubet señala como hueco en las líneas de trabajo de los estados actuales incluidos los benefactores: la reducción de las distancias sociales. La AUH busca integrar al sistema a aquellos que están afuera y lo 
hace desde la educación y la salud. De esta forma, se inserta gran cantidad de población a partir de vínculos formales con la sociedad generando en los beneficiarios de esta política jerarquizarse en tanto ciudadanos con plenos derechos.

El autor pone en cuestión las políticas centradas en la idea de igualdad de oportunidades en tanto garantía de justicia social y destaca el carácter conservador de las políticas igualitaristas clásicas por garantizar un orden que tiende a sostener en sus lugares a los distintos sectores sociales. El análisis de la brecha entre los efectos de las políticas y las situaciones sociales emergentes, nuevas, inusitadas e imprevistas que enfrentamos, pone en cuestión la imposibilidad de responder a la realidad sociohistórica si no se aborda la universalidad y la heterogeneidad que la constituyen.

Sin embargo, nos dice Dubet, sólo asegurando en primer término la universalidad, es posible la atención a la diversidad como política que promueva la justicia social. Para crear igualdad no basta con abrir los accesos a lugares antes inaccesibles para los sectores beneficiados por medidas igualitaristas. Medidas de este tipo se encontrarán con dos límites, por una parte lo que denomina techo de cristal y por la otra un posible efecto de apartheid social. Con el primero se refiere al límite superior en las posibilidades de movilidad social, un techo de máxima al que los actores sociales pueden aspirar y que está fuertemente influido por las condiciones socioculturales y económicas de base de cada sector. Con el segundo límite resalta el efecto de creación de grupos y subgrupos que comparten ciertas características comunes con el riesgo de no generar intercambios de lugares con otros sectores. Así, a pesar de los progresos relacionados a la igualdad, el mundo de los incluidos, el sistema, sigue sosteniendo espacios o jerarquías para ciertos sectores.

Estos planteos hacen resaltar la idea del autor de que las desigualdades seguirán existiendo dentro de un modelo tendiente a la igualdad y que esto trasluce el carácter conservador que estaba presente en el modelo de las posiciones. Estas desigualdades que permanecen a pesar de los cambios introducidos obligan a pensar en un modelo de justicia social que se base en la lucha contra los obstáculos a la movilidad y en particular el problema de la integración de sectores cuyas situaciones de inicio en la competencia por al igualdad son desfavorables.

La ficción de la igualdad de oportunidades también opera bajo el supuesto de no existencia de procesos de discriminación. En nombre de la diversidad se lucha contra la discriminación que se ejerce sobre algunos grupos buscando su inserción social en condiciones de igualdad con el resto de la sociedad. Ahora bien, Dubet destaca que todos los dispositivos que operan en tal sentido lo hacen sin poner en duda el orden de esas posiciones a las que se busca acceder. Lo importante es llegar a ocupar esos lugares aún al precio de sostener viejas jerarquías sobre las que se estructuran. 
Eva Vásquez

En este sentido el avance teórico del pensamiento crítico de Dubet tiene consecuencias valiosas en la medida en que nos acerca a la complejidad del problema y alerta sobre los alcances y los límites de las políticas de igualdad de posiciones y de igualdad de oportunidades proponiendo una reconfiguración de las políticas de justicia social sin que éstas queden encerradas en un conjunto de atributos vacíos. 